\title{
Parvovirus B19 Infection Mimicking Juvenile Myelomonocytic Leukemia in an Immunocompetent Child
}

\author{
Aji Mathew ${ }^{1}$, Walid Abuhammour ${ }^{2}$, Basil Fathalla ${ }^{3}$, Bosaina Otour ${ }^{4}$ \\ 1. Pediatric Pulmonology, Al Jalila Children Hospital, Dubai, ARE 2. Infectious Diseases, Al Jalila Children's Speciality \\ Hospital, Dubai, ARE 3. Rheumatology, Al Jalila Children's Speciality Hospital, Dubai, ARE 4. Paediatrics, Al Jalila \\ Children's Speciality Hospital, Dubai, ARE
}

Corresponding author: Walid Abuhammour, wabuhammour@ajch.ae

\begin{abstract}
Most of the parvovirus infections in humans are benign. Clinical manifestations of parvovirus B19 infections in children vary from erythema infectiosum in healthy children to aplastic crisis in patients with hematological disorders (such as sickle cell disease) and immunocompromised patients. Parvovirus B19 infects the erythroid progenitor cell in the bone marrow and causes transient erythroblastopenia. Transient leukoerythroblastic reaction is a rare presentation of parvovirus infection. Our case is a child presenting with fever of unknown origin (FUO) who was investigated and treated in different hospitals for FUO. He was investigated for infections, rheumatological causes, and malignancies. Clinical manifestations and bone marrow findings were mimicking juvenile myelomonocytic leukemia (JMML) but eventually diagnosed to have a parvovirus B19 infection, which resolved spontaneously in due course.
\end{abstract}

Categories: Pediatrics, Infectious Disease, Oncology

Keywords: parvovirus b19, juvenile myelomonocytic leukemia

\section{Introduction}

Human parvovirus B19 is a single-stranded DNA virus that belongs to the Parvoviridae family. Clinical manifestations of parvovirus B19 infections in children vary from erythema infectiosum in healthy children to aplastic crisis in patients with hematological disorders (such as sickle cell disease) and immunocompromised patients [1]. Parvovirus B19 infects the erythroid progenitor cell in the bone marrow and causes transient erythroblastopenia. It has been associated with transient red cell aplasia, aplastic crisis, and lupus like syndromes in children with hematological disorders and immunodeficiency [2,3]. Transient leukoerythroblastic reaction is a rare presentation of parvovirus infection $[3,4]$.

Received 05/29/2020

Review began 06/19/2020 Review ended 06/23/2020 Published 06/26/2020

\section{() Copyright 2020}

Mathew et al. This is an open access article distributed under the terms of the Creative Commons Attribution License CC-BY 4.0., which permits unrestricted use, distribution, and reproduction in any medium, provided the original author and source are credited.
We report herein a child presenting with fever of unknown origin (FUO) with clinical manifestations and bone marrow findings mimicking juvenile myelomonocytic leukemia (JMML) and leukoerythroblastic reaction who eventually diagnosed to have a parvovirus B19 infection.

\section{Case Presentation}

A previously healthy four-year-old Arab boy presented with a history of prolonged fever, generalized fatigue, and arthralgia of one-month duration. He was evaluated in other institutions without a conclusive diagnosis. He was treated with several courses of intravenous antibiotics without clinical response. Investigations during that phase of his illness revealed low hemoglobin of $9 \mathrm{gm} / \mathrm{dl}$ (normal range: 11-14) and raised inflammatory markers. On physical examination upon arrival to our center, he was noted to be febrile, pale, and ill looking. He had bilateral small 1 x $1 \mathrm{~cm}$ firm cervical lymph nodes, hepatosplenomegaly, and was unable to walk due to arthralgia of knees and ankles. Repeated workup after a week revealed a total while blood count (WBC) of $13.5 \times 10^{3} / \mathrm{mcl}$, an increased absolute neutrophil count (ANC) of $8.84 \times 10^{3} / \mathrm{mcl}$, a low absolute lymphocyte count (ALC) of $1.59 \times 10^{3} / \mathrm{mcl}$, a high absolute monocyte count (AMC) of $1.9 \times$ $10^{3} / \mathrm{mcl}(0.2-1)$, a platelet count of $147,000 / \mathrm{mcl}$, and a drop in his hemoglobin to $7.30 \mathrm{gm} / \mathrm{dl}$ (11-14). During his hospital course, he had persistent fever and the hemoglobin dropped further to $5.9 \mathrm{gm} / \mathrm{dl}$ after five days requiring packed red blood cell transfusion. Inflammatory markers were high including C-reactive protein (CRP) at $65 \mathrm{mg} / \mathrm{dl}(0-5)$, erythrocyte sedimentation rate (ESR) of $63 \mathrm{~mm} / \mathrm{hr}(0-10)$, and ferritin of 145.5 $\mathrm{mcg} / \mathrm{L}$ (4-60). Iron profile showed low serum iron and hemoglobin electrophoresis showed slightly elevated hemoglobin A2, which was suggestive of beta thalassemia trait. Direct Coombs test was negative, and G6PD screening was normal. Reticulocyte count was $0.59 \%(0.5 \%-2.5 \%)$ inappropriately low for the degree of anemia. Cultures of blood and urine were negative, and stool studies were unremarkable. Serological tests (IgG and IgM) and PCR for Epstein-Barr virus (EBV), Cytomegalovirus (CMV), Mycoplasma pneumoniae, Brucella species IgM and IgG, and enterovirus PCR were negative. Cerebrospinal fluid (CSF) analysis, culture, and virology studies, including Herpesvirus, CMV, and enterovirus, were normal. Screening for tuberculosis, including Quantiferon test and Mantoux skin test, was negative. Liver functions were normal 


\section{Cureus}

except for a slightly low albumin of $3 \mathrm{~g} / \mathrm{dl}$ (3.8-4.5). Antinuclear antibodies (ANA), anti-double stranded DNA, extractable nuclear antibodies (ENA) tests, rheumatoid factor tests, and antineutrophil cytoplasmic antibody (ANCA) tests (c-ANCA, p-ANCA, and atypical p-ANCA) were negative. He had normal immunoglobulin levels, including IgG and IgG subclasses, IgA, IgM, and IgE levels, and flow cytometry for T and B lymphocyte, and natural killer cells (NK) were normal. Tetanus, diphtheria, and pneumococcal antibody titers were normal. Serum triglycerides was $426 \mathrm{mmol} / \mathrm{L}(0-180)$ and soluble IL-2 receptor levels were high at $3,715 \mathrm{U} / \mathrm{mL}$ (223-710). New generation sequencing genetic testing for primary hemophagocytic lymphohistiocytosis panel was negative.

The blood film revealed severe microcytic hypochromic anemia with anisopoikilocytosis and eythrocytosis consistent with iron deficiency anemia combined with beta-thalassemia trait. WBC lineage showed leukoerythroblastic blood picture with leukocytosis, monocytosis, and subtle dysplastic neutrophils and was suggestive of JMML. In addition, radiological findings of abdomen ultrasonography (Figure 1) and CT of abdomen and pelvis showed mild hepatosplenomegaly with mild ascites. Therefore, a bone marrow study was performed to rule out leukemia, which showed megaloblastic changes, mild dyserythropoiesis, and subtle dysgranulopoietic changes. The bone marrow was dysplastic and suspicious of JMML; however, cytogenetics analysis for JMML was negative. Fluorescent in situ hybridization (FISH study for $\mathrm{t}(9 ; 22)$ (q34;q11.2) (BCR/ABL) DF, D7S486(7q31)/CEP 7, EGR1(5q31)/ D5S23,D5S721(5p15.2), and CEP 8) showed no chromosomal rearrangement.

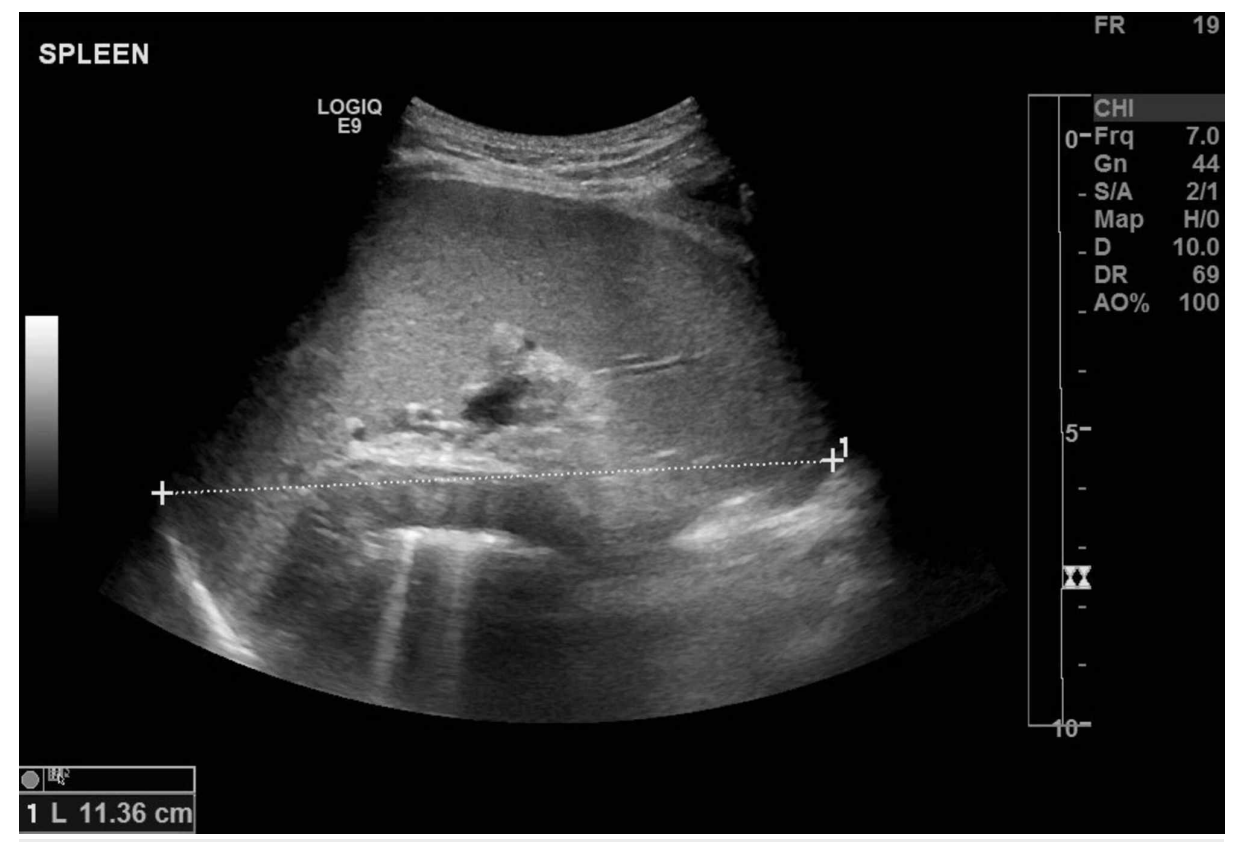

FIGURE 1: Mild splenomegaly at initial presentation

We pursued further investigations in view of lack of diagnosis. Although late in the course, we sent for parvovirus B19 blood PCR (qualitative) that detected presence of parvovirus B19 DNA. Serum parvovirus IgG titer was positive at 6.7 index units (positive >1.1) but IgM titer was negative. Meanwhile, fever started to subside gradually and he had gradual symptomatic improvement over the three-week period. His clinical examination upon discharge revealed resolution of hepatosplenomegaly (Figure 2), confirmed by repeated abdominal ultrasound. Repeated parvovirus B19 PCR after three months (this was done quantitative) was positive, and ultimately the PCR test became negative at six months after initial testing. The serum parvovirus IgG titer declined gradually to 5 index units (positive $>1.1$ ) in two months and then 3.6 index units (positive >1.1) at six months. Further follow-up during 12 months revealed the child to be doing well with no symptoms and normal physical examination. 


\section{Cureus}

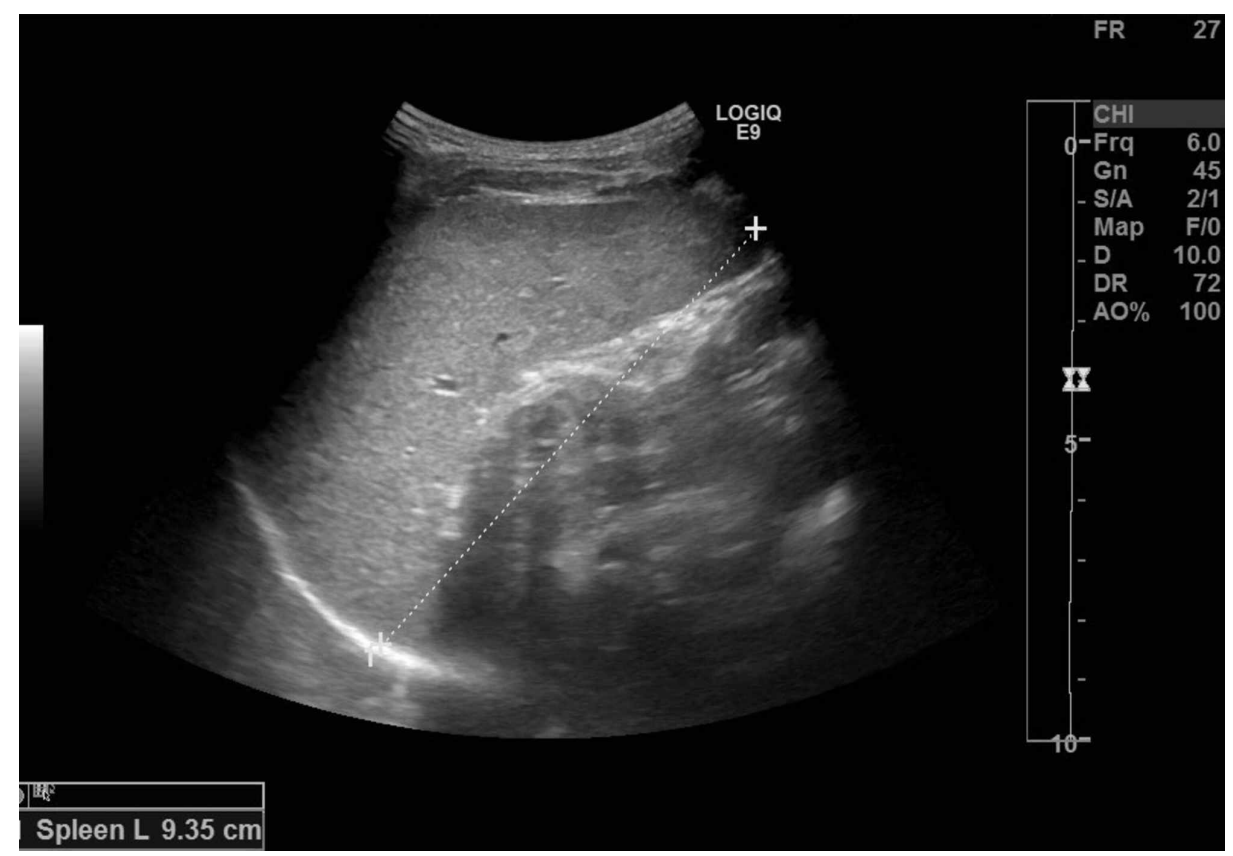

FIGURE 2: Regression of spenomegaly after three months of initial presentation

\section{Discussion}

Majority of parvovirus B19 infections are benign and asymptomatic in healthy children. The most common presentation is erythema infectiosum which is a self-limiting disorder. However, parvovirus infection can be life threatening in specific populations. Bone marrow suppression and red cell aplasia may develop in mostly patients who are immunocompromised or with hematological disorders like sickle cell disease and other hemoglobinopathies, and rarely in healthy children $[5,6]$. There are few reports of parvovirus B19 infections presenting with a prolonged course and unexpected complications, such as myocarditis and meningoencephalitis $[7,8]$. Rarely, parvovirus B19 infection can trigger a clinical course similar to systemic lupus erythematosus with nephritis, arthritis, vasculitis, and nephrotic syndrome [9]. Similar to other infections, parvovirus B19 infection can occasionally trigger transient autoantibody response, including ANA and rheumatoid factor.

Leukoerythroblastosis is a rare phenomenon that is characterized by leukocytosis and the presence of erythroid and myeloid blasts in the peripheral blood. In children, this blood picture is rare and is seen in JMML, myelofibrosis, metastatic bone marrow disease, and sometimes following viral infections. Two cases of neonatal parvovirus B19 infection presenting as transient myeloproliferation resembling JMML have been reported [10,11]. There is another reported case of an 11-month-old immune competent child presented as JMML that was also proved to be due to parvovirus B19 infection [12]. Myelodysplastic features mimicking JMML have been described in other viral diseases, such as acquired Immunodeficiency syndrome, HHV6, CMV, and EBV infection $[13,14]$.

The present case was initially suspected to be JMML in view of the clinical features of hepatosplenomegaly with anemia and dysplastic bone marrow findings. Parvovirus B19 infection as a cause of the clinical and laboratory manifestations in this case was not initially suspected, and serology as well as PCR studies were not done as part of the initial workup. However, when cytogenetic studies for JMML were negative, further workup to identify an etiology was done, including workup for parvovirus B19. Although the parvovirus B19 IgM titer was negative, we believe that the etiology was parvovirus B19 infection. This child had complete resolution of hepatosplenomegaly, anemia, and lymphadenopathy, and normalization of laboratory markers without definitive treatment. The lack of alternative etiology, positive IgG titers that declined over time, positive parvovirus PCR that eventually became negative, and spontaneous resolution of clinical features were supportive of the diagnosis of parvovirus B19 infection. In selected cases of parvovirus infection with persistent anemia, intravenous immunoglobulin (IVIG) can be a potential therapeutic option.

\section{Conclusions}

Although majority of parvovirus infections are benign, it can have rare and serious presentations, including FUO, myocarditis, and malignancies. Therefore, parvovirus B19 should be considered and early workup, including serology and PCR tests, should be done in children presenting with FUO and anemia with poor bone marrow reactivity, even in the presence of other misleading clues like organomegaly. 


\section{Additional Information \\ Disclosures}

Human subjects: Consent was obtained by all participants in this study. Conflicts of interest: In compliance with the ICMJE uniform disclosure form, all authors declare the following: Payment/services info: All authors have declared that no financial support was received from any organization for the submitted work. Financial relationships: All authors have declared that they have no financial relationships at present or within the previous three years with any organizations that might have an interest in the submitted work. Other relationships: All authors have declared that there are no other relationships or activities that could appear to have influenced the submitted work.

\section{References}

1. Geetha D, Zachary JB, Baldado HM, Kronz JD, Kraus ES: Pure red cell aplasia caused by parvovirus B19 infection in solid organ transplant recipients: a case report and review of literature. Clin Transplant. 2000, 14:586-591. 10.1034/j.1399-0012.2000.140612.x

2. Prassouli A, Papadakis V, Tsakris A, Stefanaki K, Garoufi A, Haidas S, Dracou C: Classic transient erythroblastopenia of childhood with human parvovirus B19 genome detection in the blood and bone marrow. J Pediatr Hematol Oncol. 2005, 27:333-336. 10.1097/01.mph.0000169249.72858.8c

3. Yetgin S, Aytaç Elmas S: Parvovirus-B19 and hematologic disorders. Turk J Haematol. 2010, 27:224-233. 10.5152/tjh.2010.43

4. Gupta N, Gupta R, Bakhshi S: Transient myeloproliferation mimicking JMML associated with parvovirus infection of infancy. Pediatr Blood Cancer. 2009, 52:411-413. 10.1002/pbc.21842

5. Barash J, Dushnitzky D, Sthoeger D, Bardenstein R, Barak Y: Human parvovirus B19 infection in children: uncommon clinical presentations. Isr Med Assoc J. 2002, 4:763-765.

6. Alonso-Saladrigues A, Català A, Berrueco R, Camós M, Torrebadell M, Rives S: Aplastic crisis secondary to parvovirus B19 infection as the first manifestation of an undiagnosed hereditary spherocytosis: report of a pediatric series of Spanish patients. J Pediatr Hematol Oncol. 2016, 38:81-82. 10.1097/MPH.0000000000000481

7. Spartalis M, Tzatzaki E, Spartalis E, Damaskos C, Mavrogeni S, Voudris V: Parvovirus B19 myocarditis of fulminant evolution. Cardiol Res. 2017, 8:172-175. 10.14740/cr580w

8. Zaki Mel S, Hassan SA, Seleim T, Lateef RA: Parvovirus B19 infection in children with a variety of hematological disorders. Hematology. 2006, 11:261-266. 10.1080/10245330600841089

9. Sève P, Ferry T, Koenig M, Cathebras P, Rousset H, Broussolle C: Lupus-like presentation of parvovirus B19 infection. Semin Arthritis Rheum. 2005, 34:642-648. 10.1016/j.semarthrit.2004.07.008

10. Duran R, Vatansever U, Acunaș B, Orhaner B, Demir M: Transient leukoerythroblastosis in a very low birth weight infant with parvovirus B19 infection. Int J Infect Dis. 2009, 13:e473-e475. 10.1016/j.ijid.2009.01.002

11. Ozdemir N, Akı H, Hakyemez HT, Cokuğraş FÇ, Apak H: Parvovirus B19 infection mimicking juvenile myelomonocytic leukemia. Int J Infect Dis. 2010, 14:e379-e380. 10.1016/j.ijid.2010.04.004

12. Yetgin S, Cetin M, Yenicesu I, Özaltın F, Uçkan D: Acute parvovirus B19 infection mimicking juvenile myelomonocytic leukemia. Eur J Haematol. 2000, 65:276-278. 10.1034/j.1600-0609.2000.065004276.x

13. Kirby MA, Weitzman S, Freedman MH: Juvenile chronic myelogenous leukemia: differentiation from infantile cytomegalovirus infection. Am J Pediatr Hematol Oncol. 1990, 12:292-296.

14. Herrod HG, Dow LW, Sullivan JL: Persistent Epstein-Barr virus infection mimicking juvenile chronic myelogenous leukemia: Immunologic and hematologic studies. Blood. 1983, 61:1098-1104. 